\title{
KUALITAS PELAYANAN MUSEUM GEOLOGI BANDUNG: SUATU STUDI MENGENAI PERSEPSI WISATAWAN DOMESTIK
}

\author{
Any Noor dan Wiwin Karwina \\ Jurusan Administrasi Niaga, Politeknik Negeri Bandung
}

\begin{abstract}
Geological Museum, Bandung is an educational and historical tourist attraction that mostly visited by student. As tourist attraction, Geological Museum should deliver good services in order to satisfy tourists. In order to understand the tourist perception about service quality in Geological Museum, this study aim to explore the tourist perception about service quality delivered at Geological Museum. Five dimensions of service quality which are reliability, responsiveness, empathy, assurance and tangible were asked to 127 respondents through questionnaire at Geological Museum, Bandung. Findings indicate that responsiveness dimension is the lowest point of service quality and tangible is at the highest point, although result of both dimensions is at medium level. In overall, tourist perception about Geological Museum service quality is at medium level and has the potential to be good in services.
\end{abstract}

Keywords: Service Quality, Museum Geologi

\section{PENDAHULUAN}

\subsection{Latar Belakang}

Pariwisata merupakan kegiatan yang penting bagi Indonesia, karena menghasilkan devisa terbesar kedua setelah minyak dan gas bumi (Bainfokomsumut Online, 2007). Secara ekonomi, kunjungan wisatawan mancanegara pada tahun 2007 yang mencapai 5,5 juta orang telah memberikan sumbangan devisa sebesar 5,3 miliar dolar (Pelita online, 2007) Selain sebagai penyumbang devisa bagi negara, pariwisata juga memberikan kontribusi dari sisi penyedia tenaga kerja, dimana satu dari 12,6 angkatan kerja diciptakan di sektor pariwisata (Cirus, 2002). Sehingga dapat dipastikan bahwa pariwisata merupakan industri yang penting bagi Indonesia.

Dengan jumlah kunjungan wisatawan ke daerah Jawa Barat pada akhir November 2007 mencapai 31 juta orang (Depkominfo online, 2007) diyakini bahwa Jawa Barat merupakan salah satu daerah tujuan wisata yang penting di Indonesia terutama bagi wisatawan domestik. Hal ini dikarenakan terdapat banyak objek wisata potensial di Jawa Barat, seperti keindahan alam, keaekaragaman budaya, tingginya nilai sejarah, dan beragamnya bangunan bersejarah (heritage) di kota Bandung serta bervariasinya kuliner kota Bandung. Potensi wisata inilah yang menimbulkan motivasi kepada wisatawan baik wisatawan nusantara maupun wisatawan mancanegara untuk datang mengunjungi Jawa Barat.

Salah satu atraksi wisata sejarah sekaligus pendidikan yang terdapat di kota
Bandung adalah Museum Geologi. Pada mulanya, Museum Geologi yang didirikan pemerintah Hindia Belanda pada tahun 1929 berfungsi sebagai perkantoran yang dilengkapi laboratorium dan tempat penyimpanan hasil penyelidikan geologi dan pertambangan. Namun, pada tahap selanjutnya fungsi museum berkembanga menjadi lebih luas lagi, yaitu sebagai sarana penelitian, pendidikan dan penyedia berbagai informasi ilmu kebumian serta objek wisata (Morissan, 2002). Berbagai koleksi terdapat di Museum Geologi, seperti fosil tengkorak manusia dan binatang yang berumur lebih dari 1 juta tahun dari sejarah Sangiran, koleksi berbagai jenis bebatuan, dan proses terjadinya bumi (Ernes, 2004).

Beragam koleksi yang ada di Museum Geologi merupakan potensi yang dapat menarik minat wisatawan untuk datang berkunjung, terutama bagi pelajar yang $80 \%$ mendominasi kunjungan ke Museum Geologi (Museum Geologi, 2008). Tabel 1 memperlihatkan jumlah pengunjung Museum Geologi yang mengalami peningkatan selama tahun 2004 sampai 2007, walaupun terdapat sedikit penurunan disepanjang tahun 2003 dan tahun 2008. Hal ini tentunya memperlihatkan bahwa Museum Geologi merupakan objek wisata yang potensial di Jawa Barat, khususnya kota Bandung. 
TABEL 1

JUMLAH PENGUNJUNG MUSEUM GEOLOGI TAHUN $2003-2008$

\begin{tabular}{|c|c|}
\hline Tahun & Jumlah \\
\hline 2003 & 12.358 \\
\hline 2004 & 11.147 \\
\hline 2005 & 16.500 \\
\hline 2006 & 18.771 \\
\hline 2007 & 30.443 \\
\hline 2008 & 29.259 \\
\hline
\end{tabular}

Sumber: Museum Geologi, 2008

5. Besarnya jumlah wisatawan yang datang ke Museum Geologi tentunya memberikan gambaran besarnya minat wisatawan untuk berwisata sejarah dan edukasi di Museum Geologi. Mengingat kualitas pelayanan merupakan salah satu faktor yang mungkin menyebabkan terjadinya penurunan dan peningkatan jumlah pengunjung di Museum Geologi Bandung, maka studi ini difokuskan pada penilaian persepsi wisatawan tentang kualitas pelayanan di Museum Geologi Bandung.

\section{KAJIAN PUSTAKA}

\subsection{Museum}

Sudah sejak lama dipercaya bahwa museum merupakan tempat yang penuh dengan sejarah dan latar belakang kebudayaan suatu daerah yang harus dijaga keberadaannya untuk generasi masa yang akan datang. Museum merupakan tempat orang untuk mengeksplorasi koleksi sebagai suatu inspirasi, tempat belajar dan tempat untuk mencari kesenangan. Definisi museum diberikan oleh The UK Museum Association (1998), sebagai institusi yang mengkoleksi dan memproteksi artifak serta beragam benda lainnya yang memiliki keaslian yang diperuntukkan bagi masyarakat.

Museum melayani pengunjung sepanjang tahun, menerima kunjungan masyarakat dari berbagai daerah. Biasanya museum yang dikelola oleh pemerintah tidak memungut biaya bagi setiap pengunjung yang datang. Dengan tidak diterapkannya biaya untuk setiap kunjungan ke museum, maka pelayanan yang diberikan juga sangat terbatas. Sehingga, untuk meningkatkan pelayanan museum kepada para pengunjung, banyak museum mulai menerapkan biaya kunjungan karena rendahnya dana yang dimiliki museum untuk operasional (Wilson and Boyle, 2004).

\subsection{Kualitas Pelayanan}

Kandampully dalam Kvist dan Klefsjo (2006) menegaskan bahwa kualitas merupakan hal penting dalam kegiatan pariwisata sebagai alat untuk menghadapi masa depan. Sama hal nya dengan WTO (2003), yang mengemukakan bahwa kualitas dalam kegiatan pariwisata didefinisikan sebagai

... the satisfaction of all the legitimate product and service needs, requirements and expectations of the consumer, at an acceptable price, in conformity with the underlying quality determinants such as safety and security, hygiene, accessibility, transparency, authenticity and harmony of the tourism activity concerned with its human and natural environment.

Hal tersebut ditegaskan oleh Deming dalam Kvist and Klefsjo (2006) bahwa kualitas harus ditujukan pada kebutuhan konsumen saat ini dan pada masa yang akan datang.

Definisi mengenai pelayanan telah banyak dielaborasi oleh para ahli, salah satunya adalah definisi yang dikemukanan oleh Gronross dalam Kvist dan klefsjo (2006):

A service is an activity or series of activities of a more less intangible nature that normally, but not necessarily, takes place in the interaction between the customer and service employees and/ or physical resources or goods and/ or systems of the service provider, which are provided as solutions to customer problems.

Meskipun banyak pendekatan mengenai kualitas pelayanan dikemukakan, beberapa ahli seperti Edvardson dkk, Bergman dan Klefsjo, Gummesson dalam Kvist dan Klefsjo, (2006) mengungkapkan beberapa perbedaan penting mengenai kualitas pelayanan barang dan jasa sebagai berikut:

1. Service tidak berwujud, sehingga sulit untuk dijelaskan secara spesifik dan diukur pelayanannya

2. Service dapat diidentifikasi lebih subjektif

3. Konsumen memiliki peranan penting dalam menciptakan pelayanan

4. Service terdiri dari beberapa aktifitas berbeda sehingga sulit bagi konsumen untuk melakukan penilaian sebelum dibeli.

5. Service terdiri dari beberapa bagian dan penilaian konsumen tidak dapat dipisahkan berdasarkan bagian-bagian tersebut, tetapi biasanya dilakukan penilaian secara keseluruhan. 


\subsection{Dimensi Kualitas Pelayanan}

Parasuraman dkk dalam Tjiptono (2006), mengemukakan sepuluh dimensi kualitas pelayanan yang tepat untuk digunakan pada bisnis pelayanan atau jasa. Dimensi yang dikemukakan oleh Parasuraman dkk dikenal dengan istilah service quality atau SERVQUAL, terdiri dari:

1. Reliability, mencakup konsistensi kerja dan kemampuan untuk dipercaya. Konsistensi kerja berarti perusahaan memberikan pelayanannya dengan tepat mulai dari awal sampai akhir. Kemampuan dapat dipercaya salah satunya adalah pemenuhan janji.

2. Responsiveness, berarti kesediaan atau kesiapan penyedian layanan untuk memberikan pelayanan yang dibutuhkan pelanggan.

3. Competence, artinya setiap orang dalam perusahaan jasa memiliki keterampilan dan pengetahuan agar dapat memberikan pelayanannya kepada pelanggan.

4. Acces, meliputi kemudahan untuk dihubungi atau ditemui.

5. Courtesy, sikap sopan santun yang dimiliki penyedia layanan.

6. Communication, artinya memberi informasi kepada pelanggan dengan bahasa yang komunikatif, dan mendengarkan saran dan keluhan pelanggan.

7. Credibility, yaitu sifat jujur dan dapat dipercaya. Kredibilitas mencakup reputasi perusahaan dan interaksi contact personel dengan pelanggan.

8. Security, yaitu aman dari resiko, bahaya dan keragu-raguan.

9. Understanding/ knowing the customer, usaha dalam memahami kebutuhan pelanggan.

10. Tangibles, yaitu bukti fisik dari jasa, berupa fasilitas fisik dan peralatan yang digunakan.

Sementara Zeithaml dan Bitner (2006) mengemukakan lima dimensi kualitas pelayanan yang dapat diadopsi oleh perusahaan yang bergerak dibidang jasa yang memungkinkan tidak terjadinya overlap dimensi. Kelima dimensi tersebut adalah:

1. Reliability, kemampuan perusahaan dalam memberikan pelayanan sesuai yang dijanjikan secara akurat dan terpercaya.

2. Responsiveness, kemauan dan kemampuan para karyawan untuk membantu konsumen dan merespon permintaan, pertanyaan dan keluhan konsumen dengan cepat dan tepat.

3. Assurance, berkaitan dengan kepastian pengetahuan, kesopansantunan, dan kemampuan para pegawai perusahaan untuk menumbuhkan rasa percaya konsumen kepada perusahaan.

4. Empathy, memahami masalah konsumen dan bertindak demi kepentingan konsumen, serta memberikan perhatian personal kepada konsumen dan memiliki jam operasional yang nyaman.

5. Tangible atau bukti fisik, berkenaan dengan fasilias fisik, perlengkapan dan peralatan yang digunkanan serta penampilan pegawainya.

Dua dimensi kualitas pelayanan diatas memiliki arti yang hampir sama. Jika digabungkan, maka dengan menggunakan dimensi Zeithaml dan Bitner (2006) telah dapat memenuhi keseluruhan dimensi kualitas pelayanan yang diperlukan.

\subsection{Persepsi wisatawan}

Kualitas harus dimulai dari kebutuhan pelanggan yang berakhir pada persepsi pelanggan. Persepsi merupakan proses seseorang dalam memilih, mengatur dan mengartikan informasi yang diterima menjadi suatu yang bermakna (Kotler dan Armstrong, 2006). Suhartanto (2008) menjelaskan persepsi sebagai suatu proses bagaimana seseorang mengelola dan memakai stimuli yang ia terima. Setiadi (2003) juga menjelaskan persepsi adalah suatu proses yang timbul akibat adanya stimuli (Setiadi, 2003). Dengan demikian, persepsi wisatawan merupakan proses dimana wisatawan menerima dan mengartikan stimuli yang diterimanya menjadi suatu yang bermakna. Dalam hal ini, pengolahan dan permberian makna terhadap stimuli yang diterima terjadi dalam pikiran seseorang atau wisatawan yang berkunjung ke Museum Geologi.

Kualitas yang baik pada Museum Geologi tidak dilihat dari sisi penyedia jasa, melainkan dari sudut pandang atau persepsi wisatawan. Wisatawan Museum Geologi akan merasakan palayanan yang diterima selama kunjungannya, sehingga dalam studi ini, wisatawan yang harus menilai kualitas pelayanan yang mereka dapatkan selama kunjungan ke Museum Geologi.

\section{METODE PENELITIAN}

Secara umum tujuan dari studi ini adalah untuk mengetahui persepsi wisatawan terhadap kualitas pelayanan Musesum Geologi Bandung. Untuk mencapai tujuan tersebut, metode deskriptif digunakan dengan maksud mengumpulkan, menganalisis dan menyimpulkan data berdasarkan fakta. Kuesioner yang diisi sendiri oleh responden 
(self administered) yang dibagikan kepada 127 orang responden di Museum Geologi Bandung. Hal ini dilakukan untuk memastikan bahwa responden telah mendapatkan pelayanan atas kunjungan ke Museum Geologi dan dapat memberikan persepsi atas pelayanan yang baru saja dirasakan.

\subsection{Operasionalisasi Variabel}

Studi ini memfokuskan pada persepsi konsumen terhadap kualitas pelayanan yang diberikan oleh Museum Geologi Bandung, sehingga variabel penting dalam penelitian ini adalah kualitas pelayanan. Dengan menggunakan dimensi kualitas pelayanan yang dikemukakan oleh Parasuraman dkk dan Zeithaml dan Bitner, maka operasionalisasi variabel studi ini tampak pada tabel berikut.

\section{TABEL 2}

OPERASIONALISASI VARIABEL

\begin{tabular}{|c|c|c|}
\hline Variabel & $\begin{array}{c}\text { Sub } \\
\text { Variabel }\end{array}$ & Indikator \\
\hline \multirow{17}{*}{$\begin{array}{l}\text { Kualitas } \\
\text { pelayanan } \\
\text { (Persepsi } \\
\text { wisatawan } \\
\text { terhadap } \\
\text { pelayanan } \\
\text { yang } \\
\text { diterima.) }\end{array}$} & \multirow[t]{2}{*}{ 1. Reliability } & $\begin{array}{ll}\text { a. } & \text { Keterangan } \\
\text { koleksi }\end{array}$ \\
\hline & & $\begin{array}{l}\text { b. Pemandu } \\
\text { wisata }\end{array}$ \\
\hline & \multirow[t]{5}{*}{$\begin{array}{l}\text { 2. Responsiv } \\
\text { e-ness }\end{array}$} & $\begin{array}{ll}\text { a. } & \begin{array}{l}\text { Kecepatan } \\
\text { menjawab } \\
\text { pertanyaan }\end{array} \\
\end{array}$ \\
\hline & & $\begin{array}{ll}\text { b. } & \begin{array}{l}\text { Ketepatan } \\
\text { menjawab } \\
\text { pertanyaan }\end{array} \\
\end{array}$ \\
\hline & & $\begin{array}{l}\text { c. Kecepatan } \\
\text { menanggap } \\
\text { i keluhan }\end{array}$ \\
\hline & & $\begin{array}{ll}\text { d. } & \text { Ketepatan } \\
\text { menanggap } \\
\text { i keluhan } \\
\end{array}$ \\
\hline & & $\begin{array}{ll}\text { e. } & \text { Kesediaan } \\
\text { membantu }\end{array}$ \\
\hline & \multirow[t]{3}{*}{ 3. Assurance } & $\begin{array}{ll}\text { a. } & \begin{array}{l}\text { Keamanan } \\
\text { penitipan }\end{array} \\
\end{array}$ \\
\hline & & $\begin{array}{l}\text { b. Pengetahua } \\
\mathrm{n} \text { pemandu }\end{array}$ \\
\hline & & c. Reputasi \\
\hline & \multirow[t]{3}{*}{ 4. Empathy } & $\begin{array}{ll}\text { a. } & \begin{array}{l}\text { Perhatian } \\
\text { petugas }\end{array} \\
\end{array}$ \\
\hline & & $\begin{array}{ll}\text { b. } & \begin{array}{l}\text { Keramahan } \\
\text { petugas }\end{array}\end{array}$ \\
\hline & & $\begin{array}{ll}\text { c. Kebutuhan } \\
\text { wisatawan }\end{array}$ \\
\hline & \multirow[t]{4}{*}{ 5. Tangible } & a. Fasilitas \\
\hline & & $\begin{array}{l}\text { b. Tempat } \\
\text { parkir }\end{array}$ \\
\hline & & $\begin{array}{l}\text { c. Kenyaman } \\
\text { an ruangan }\end{array}$ \\
\hline & & $\begin{array}{l}\text { d. Kebersihan } \\
\text { ruangan }\end{array}$ \\
\hline
\end{tabular}

\begin{tabular}{|l|l|l|}
\hline Variabel & \multicolumn{1}{|c|}{$\begin{array}{c}\text { Sub } \\
\text { Variabel }\end{array}$} & \multicolumn{1}{|l|}{ Indikator } \\
\hline \multirow{4}{*}{} & & e. $\begin{array}{l}\text { Sound } \\
\text { system }\end{array}$ \\
\cline { 3 - 3 } & & f. $\begin{array}{l}\text { Tata cahaya } \\
\text { ruangan }\end{array}$ \\
\cline { 3 - 3 } & & g. $\begin{array}{l}\text { Koleksi } \\
\text { benda }\end{array}$ \\
\cline { 3 - 3 } & h. $\begin{array}{l}\text { Penampilan } \\
\text { petugas }\end{array}$ \\
\hline
\end{tabular}

\section{IV.HASIL PENELITIAN \\ DAN PEMBAHASAN}

\subsection{Karakteristik Responden}

Responden pada penelitian ini terdiri dari 90 orang wanita dan 37 orang pria dengan tingkat pendidikan pada jenjang Sekolah Menengah Pertama sebanyak 41 orang dan Sekolah Menengah Atas sebanyak 30 orang. Sementara, 56 orang lainnya adalah pada tingkat pendidikan yang lebih tinggi yaitu Diploma 3, Diploma 1 dan Sarjana. 


\section{GRAFIK 1 \\ PROFIL RESPONDEN BERDASARKAN TINGKAT PENDIDIKAN}

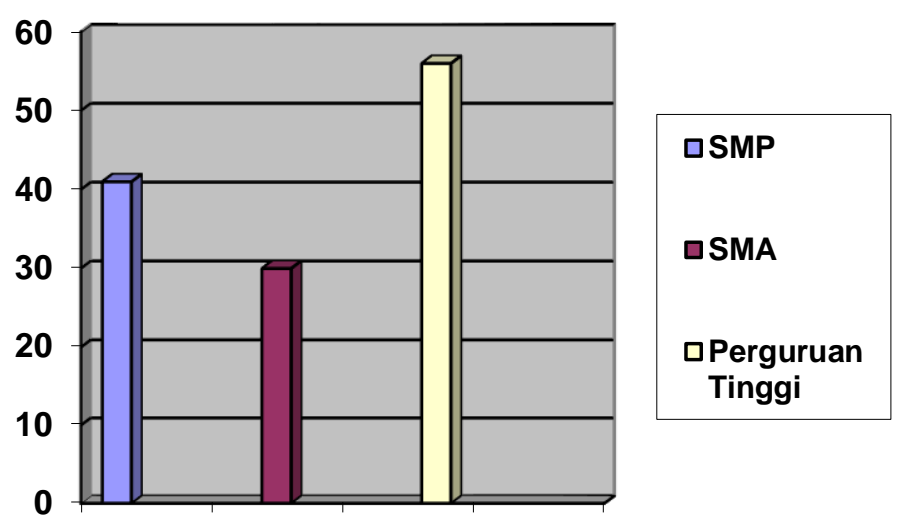

Tingginya jumlah kunjungan pelajar di Museum Geologi Bandung dikarenakan pada saat kuesioner disebar, banyak pelajar yang mengunjungi Museum Geologi, dan pada saat yang sama, beberapa sekolah dari berbagai daerah juga mengunjungi Museum Geologi. Sesuai dengan fungsi museum sebagai tempat untuk belajar dan mengenal sejarah dan kebudayaan, maka tepat apabila Museum Geologi dipenuhi oleh pelajar dari berbagai sekolah yang telah menjadwalkan kunjungannya ke Museum Geologi.

Sesuai dengan karakteristik tingkat pendidikan responden yang mengunjungi Museum Geologi Bandung, maka usia responden juga berada pada rentang usia antara 15 tahun - 25 tahun. Hal tersebut menjadi pertimbangan bahwa tingginya tingkat kunjungan pelajar ke Museum Geologi didasarkan pada kepentingan yang berhubungan dengan pendidikan, meningkatkan pengetahuan dan menambah wawasan pelajar pada rentang usia tersebut. Berdasarkan hal tersebut, maka profil responden berdasarkan usia tampak pada grafik berikut.

\section{GRAFIK 2 \\ PROFIL RESPONDEN BERDASARKAN USIA}

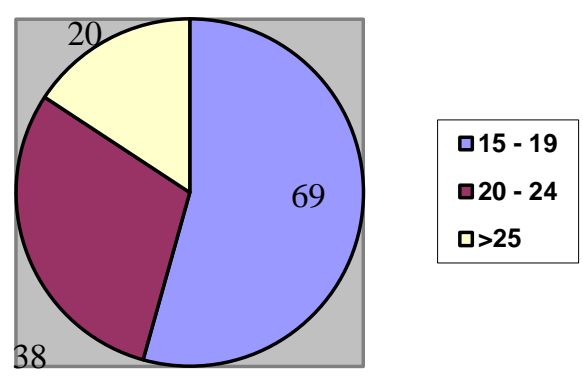

Karena mayoritas wisatawan yang berkunjung ke Museum Geologi adalah pelajar, dan salah satu fungsi museum adalah memberikan pelayanan kepada masyarakat luas, maka daerah asal wisatawan juga merupakan hal yang penting untuk diketahui. Hal ini untuk menjelaskan bagaimana museum memberikan pelayanan kepada wisatawan yang berasal dari daerah yang berbeda. Profil responden berdasarkan daerah asal kunjungan terlihat pada tabel di bawah.

TABEL 3

PROFIL RESPONDEN BERDASARKAN

DAERAH ASAL

\begin{tabular}{|c|l|c|c|}
\hline No & $\begin{array}{c}\text { Daerah } \\
\text { Asal }\end{array}$ & Frekuensi & Persentase \\
\hline 1 & Bandung & 98 & 77.2 \\
\hline 2 & Jakarta & 5 & 3.9 \\
\hline 3 & Cirebon & 4 & 3.1 \\
\hline 4 & Garut & 4 & 3.1 \\
\hline 5 & Surabaya & 4 & 3.1 \\
\hline 6 & Lainnya & 12 & 9.7 \\
\hline
\end{tabular}


Berdasarkan tabel di atas mengenai daerah asal wisatawan, wisatawan kota Bandung masih banyak mendominasi kunjungan, hal ini dimungkinkan karena banyak sekolah menengah di Kota Bandung menjadwalkan kunjungan siswa dari sekolahnya ke Museum Geologi karena berhubungan dengan mata pelajaran di sekolah. Namun demikian, kunjungan wisatawan dari daerah lain juga banyak dilakukan untuk kepentingan pendidikan pada tingkat sekolah menengah. Daerah asal wisatawan terjauh dalam studi ini berasal dari Surabaya. Beberapa daerah asal kunjungan ke Museum Geologi berasal dari Jakarta, Cirebon, Garut dan daerah lainnya yang terdiri dari Kuningan, Tasikmalaya, Karawang, Bekasi dan Bogor. Daerah asal tersebut merupakan daerah yang secara gografis letaknya berada disekitar kota Bandung dan dapat ditempuh dalam waktu yang tidak terlalu lama.

\subsection{Persepsi responden terhadap Reliability \\ Museum Geologi \\ Dua unsur reliability pada Museum} Geologi memiliki nilai rata-rata 3,76 (dari skala 5). Tabel 4 menjelaskan, bahwa penulisan tentang keterangan koleksi yang ada di Museum Geologi $(3,88)$ sedikit lebih baik daripada informasi tentang benda-benda yang ada di Museum yang dijelaskan secara langsung oleh pemandu wisata $(3,36)$. Hal ini berarti bahwa secara keseluruhan informasi yang diberikan baik secara tertulis maupun oleh pemandu wisata merupakan informasi yang akurat dan dapat dipercaya walaupun pada tingkat cukup dan mengarah pada baik.

TABEL 4

ANALISIS DESKRIPTIF BERDASARKAN SUB-VARIABEL RELIABILITY

\begin{tabular}{|c|c|c|}
\hline No & Item & $\begin{array}{l}\text { Rata- } \\
\text { rata }\end{array}$ \\
\hline 1 & $\begin{array}{l}\text { Keterangan koleksi } \\
\text { dalam bentuk tulisan }\end{array}$ & 3.88 \\
\hline 2 & $\begin{array}{l}\text { Keterangan koleksi } \\
\text { oleh pemandu wisata }\end{array}$ & 3.63 \\
\hline & Rata-rata & 3.76 \\
\hline
\end{tabular}

\subsection{Persepsi responden terhadap Responsiveness Museum Geologi}

Tabel selanjutnya merupakan persepsi wisatawan terhadap responsiveness karyawan Museum Geologi Bandung. Terhadap dimensi responsiveness yang terdiri dari kemauan dan kemampuan karyawan Museum Geologi dalam membantu wisatawan, nilai rata-rata persepsi responsiveness dinilai cukup $(3,53)$. Penilaian wisatawan berkisar antara 3,36-3,89. Namun demikian dengan angka ini, penilaian berada pada kategori cukup. Hal ini mengindikasikan bahwa kemampuan karyawan Museum Geologi dalam membantu wisatawan ada pada penilaian cukup. Persepsi wisatawan mengenai kesediaan karyawan membantu wisatawan yang memiliki nilai tertinggi dan mendekati baik merupakan hal penting yang yang dimiliki oleh karyawan Museum Geologi.

TABEL 5

ANALISIS DESKRIPTIF

BERDASARKAN SUB-VARIABEL RESPONSIVENESS

\begin{tabular}{|c|l|c|}
\hline No & \multicolumn{1}{|c|}{ Item } & $\begin{array}{c}\text { Rata- } \\
\text { rata }\end{array}$ \\
\hline 1 & $\begin{array}{l}\text { Menjawab pertanyaan } \\
\text { wisatawan dengan cepat }\end{array}$ & 3.36 \\
\hline 2 & $\begin{array}{l}\text { Menjawab pertanyaan } \\
\text { wisatawan dengan tepat }\end{array}$ & 3.46 \\
\hline 3 & $\begin{array}{l}\text { Menanggapi keluhan } \\
\text { wisatawan dengan cepat }\end{array}$ & 3.44 \\
\hline 4 & $\begin{array}{l}\text { Menanggapi keluhan } \\
\text { wisatawan dengan tepat }\end{array}$ & 3.48 \\
\hline 5 & $\begin{array}{l}\text { Kesediaan karyawan } \\
\text { membantu wisatawan }\end{array}$ & 3.89 \\
\hline & \multicolumn{2}{|c|}{ Rata-rata } \\
\hline
\end{tabular}

\subsection{Persepsi responden terhadap Assurance Museum Geologi}

Assurance merupakan kepastian akan pengetahuan karyawan dan kemampuan pegawai museum untuk menumbuhkan rasa percaya wisatawan kepada Museum Geologi. Tabel di bawah ini merupakan persepsi wisatawan terhadap assurance Museum Geologi.

\section{TABEL 6}

ANALISIS DESKRIPTIF

BERDASARKAN SUB-VARIABEL ASSURANCE

\begin{tabular}{|c|l|c|}
\hline No & \multicolumn{1}{|c|}{ Item } & $\begin{array}{c}\text { Rata- } \\
\text { rata }\end{array}$ \\
\hline 1 & $\begin{array}{l}\text { Keamanan tempat } \\
\text { penitipan barang }\end{array}$ & 3.51 \\
\hline 2 & $\begin{array}{l}\text { Pengetahuan } \\
\text { pemandu wisata }\end{array}$ & 3.77 \\
\hline 3 & $\begin{array}{l}\text { Reputasi Museum } \\
\text { Geologi }\end{array}$ & 3.99 \\
\hline & \multicolumn{1}{|c|}{ Rata-rata } & $\mathbf{3 . 7 6}$ \\
\hline
\end{tabular}

Berdasarkan analisis terhadap assurance dapat dikatakan bahwa dengan nilai 3,99 (hampir mencapai 4,00) wisatawan mempersepsikan reputasi museum Geologi 
adalah baik. Nilai terkecil untuk dimensi assurance adalah pada keamanan tempat penitipan barang $(3,51)$, dengan demikian dapat dipersepsikan bahwa wisatawan menilai cukup terhadap keamanan tempat penitipan barang. Secara keseluruhan, dengan nilai ratarata 3,76 dapat dikatakan bahwa assurance di Museum geologi dipersepsikan konsumen cukup yang cenderung mengarah ke baik.

\subsection{Persepsi responden terhadap sub} variabelEmpathy Museum Geologi

Tabel selanjutnya menjelaskan empathy petugas Museum Geologi rata-rata berada pada tingkatan cukup $(3,68)$. Namun demikian, nilai tertinggi empathy ada pada keramahan petugas yang memiliki nilai 4,06 sehingga dapat dipersepsikan bahwa petugas memiliki keramahan yang baik. Sementara itu, nilai terendah adalah 3,37 yang berarti cukup merupakan persepsi wisatawan untuk pengetahuan petugas akan kebutuhan wisatawan selama berada di Museum Geologi.

TABEL 7

ANALISIS DESKRIPTIF BERDASARKAN SUB-VARIABEL EMPATHY

\begin{tabular}{|c|c|c|}
\hline No & Item & $\begin{array}{c}\text { Rata- } \\
\text { rata }\end{array}$ \\
\hline 1 & Perhatian petugas & 3.60 \\
\hline 2 & Keramahan petugas & 4.06 \\
\hline 3 & $\begin{array}{l}\text { Petugas mengetahui } \\
\text { kebutuhan wisatawan }\end{array}$ & 3.37 \\
\hline & Rata-rata & 3.68 \\
\hline
\end{tabular}

4.6 Persepsi responden terhadap sub variabel Tangible Museum Geologi

Tabel berikut memperlihatkan hasil analisa deskriptif untuk subvariabel tangible, dimana nilai rata-rata persepsi wisatawan untuk tangible adalah 3,80 yang berarti wisatawan mempersepsikan tangible di Museum Geologi cukup dan cenderung mendekati baik. Penilaian wisatawan terhadap tempat parkir $(3,44)$, fasilitas $(3,54)$, sound system $(3,59)$ dan kenyamanan ruangan $(3,77)$ memiliki angka yang dipersepsikan cukup oleh wisatawan. Sementara nilai tata cahaya ruangan $(3,92)$, penampilan petugas $(3,92)$ dan koleksi benda $(3,94)$ walaupun berada pada penilaian cukup, namum nilai tersebut mendekati baik. Diantara kedelapan hal yang ditanyakan dalam sub variabel tangible, ternyata kebersihan ruangan di Museum geologi memiliki nilai tertinggi $(4,26)$, hal ini berarti kebersihan di Museum Geologi adalah baik dan bahkan mengarah pada penilaian persepsi yang sangat baik.

TABEL 8

ANALISIS DESKRIPTIF BERDASARKAN SUB-VARIABEL TANGIBLE

\begin{tabular}{|c|c|c|}
\hline No & Item & $\begin{array}{c}\text { Rata- } \\
\text { rata }\end{array}$ \\
\hline 1 & Fasilitas & 3.54 \\
\hline 2 & Tempat parkir & 3.44 \\
\hline 3 & Kenyamanan ruangan & 3.77 \\
\hline 4 & Kebersihan ruangan & 4.26 \\
\hline 5 & Sound system & 3.59 \\
\hline 6 & Tata cahaya ruangan & 3.92 \\
\hline 7 & Koleksi benda & 3.94 \\
\hline \multirow[t]{2}{*}{8} & Penampilan petugas & 3.92 \\
\hline & Rata-rata & 3.80 \\
\hline
\end{tabular}

4.7 Persepsi responden terhadap kualitas pelayanan Museum Geologi

Secara keseluruhan persepsi wisatawan terhadap kualitas pelayanan Museum Geologi Bandung tampak pada tabel berikut ini.

TABEL 9

ANALISIS DESKRIPTIF KUALITAS PELAYANAN MUSEUM GEOLOGI BANDUNG

\begin{tabular}{|c|c|c|}
\hline No & Item & $\begin{array}{c}\text { Rata- } \\
\text { rata }\end{array}$ \\
\hline 1 & Reliability & 3.76 \\
\hline 2 & Responsiveness & 3.53 \\
\hline 3 & Assurance & 3.76 \\
\hline 4 & Empathy & 3.68 \\
\hline 5 & Tangible & 3.80 \\
\hline & Rata-rata & 3.70 \\
\hline
\end{tabular}

Rata-rata nilai persepsi responden terhadap kualitas pelayanan Museum Geologi berada pada tingkat cukup yang mengarah pada penilaian yang baik $(3,70)$. Persepsi wisatawan mengenai kualitas pelayanan Museum Geologi yang paling rendah adalah responsiveness $(3,53)$ dan persepsi wisatawan tertinggi mengenai kualitas pelayanan Museum Geologi adalah mengenai tangible. Walaupun masih berada pada kategori cukup, namun nilai persepsi mengenai reliability $(3,76)$, assurance $(3,76)$ dan tangible $(3,80)$ mendekati angka 4 yang berarti mengarah kepada baik. Sementara persepsi mengenai empathy (3,68), memiliki nilai yang sedikit lebih rendah yang dipersepsikan sebagai cukup.

. KESIMPULAN DAN REKOMENDASI Studi ini menggambarkan bahwa kualitas pelayanan Museum Geologi Bandung 
berada pada tingkat cukup yang mengarah kepada baik. Lima dimensi kualitas pelayanan yang digunakan dalam studi ini adalah reliability, responsiveness, assurance, empathy dan tangible. Hasil studi menunjukkan bahwa dimensi responsiveness merupakan dimensi yang memiliki nilai persepsi wisatawan terendah, sementara yang paling tinggi adalah dimensi tangible. Walaupun secara keseluruhan kelima dimensi kualitas pelayanan dalam studi ini hanya dipersepsikan cukup oleh konsumen, tetapi nilai persepsi tersebut mengarah kepada penilaiain baik.

\section{DAFTAR PUSTAKA}

Bainfokomsumut (2008), Penghapusan ESKA di Lingkungan Pariwisata. Homepage:http://www.bainfokomsumu t.go.id/open.php?id=277\&db=artikel

Cirus (2002), Center for Indonesian Regional and Urban Studies. Diakses pada: www.cirus.com

Depkominfo (2007), Kunjungan Wisatawan di Jawa Barat Mencapai 31 Juta Orang. Diakses pada: http://www.depkominfo.go.id/portal/?a $\mathrm{ct}=$ detail\& $\bmod =$ berita $\&$ view $=1 \& \mathrm{id}=\mathrm{B}$ RT071227170901, Juni

Ernes. (2004). Wisata Alam Indonesia. Jakarta: Restu Agung.

Kotler, Philip dan Armstrong, Gary. (2006). Principle of Marketing. United State America: Pearson Prentice Hall.

Kvist, AJ dan klefsjo, B 92006), Which service quality dimensions are important in inbound tourism? A case study in a peripheral location, Managing Service Quality Journal, Vol 16, No. 5, 2006

Diakses pada: www.emeraldinsight.com

Morrisan. (2002). Petunjuk Wisata Lengkap Jawa-Bali. Jakarta: PT Galia Indonesia.

Museum Geologi, Perkembangan Jumlah Wisatawan Museum Geologi (2008)

Pelita online (2007), Genjot devisa pariwisata, Harian Umum Pelita, online

Setiadi, Nugroho J. (2003). Perilaku Konsumen. Jakarta: Prenada Media.

Suhartanto, Dwi. (2008). Perilaku Konsumen Indonesia. Bandung: Guardaya Intimarta.

Tjiptono, Fandy. (2006). Manajemen Jasa. Yogyakarta: Andi.

UK Museums Association (1998)Diakses pada:www.museumsassociation.org

Wilson, L dan Boyle, E (2004), The role of partnership in the delivery of local government museum services, a case study from Northern Ireland, International journal of Public sector Management, Emerald Group Publishing Limited.

Diakses pada: www.emeraldinsight.com

WTO (2003), World Tourism Organisation Diakses pada: www.world-tourism.org

Zeithmal, V.A., Bitner M.J., dan Gremler D.D (2006). Sevice Marketing $4^{\text {th }}$ Edition Singapore, Mc Graw Hill

Zeithmal, V.A dan Bitner M.J. (1996). Sevice Marketing. New York: Mc Graw Hill 